\section{Conflicto, diálogo y mediación: un balance de las relaciones la Iglesia y el Estado en la Revolución Cubana}

\author{
Conflict, Dialogue and Mediation: The Church and State \\ relations in Cuban Revolution
}

\author{
Marcos Antonio da Silva \\ UNIVERSIDADE FEDERAL DA GRANDE DOURADOS \\ BRASILIA \\ $\triangle$ marocam@terra.com.br \\ Lucimara Inácio do Prado da Silva \\ UNIVERSIDADE ESTADUAL DE MATO GROSSO DO SUL \\ BRASILIA \\ Lucimara95@hotmail.com
}

Anuario Latinoamericano Ciencias Políticas

y Relaciones Internacionales vol. 3, 2016

pp. $35-52$

DOI: $10.17951 /$ al.2016.3.35

\title{
RESUMEN
}

Este trabajo analiza la relación entre la Iglesia católica y el Estado en Cuba desde el inicio del proceso revolucionario (1959) hasta nuestros días. En este sentido, nos fijamos en tres momentos claves: la tensión y la distancia a raíz de la transición al socialismo desarrollado en el país; el acercamiento que culminó con la visita del Papa Juan Pablo II en los años 90, todavía bajo el impacto de la caída del bloque soviético y el aislamiento internacional del país; y finalmente, las relaciones recientes, marcadas por la visita del Papa, ahora emérito, Benedicto XVI y la afirmación de la Iglesia católica como el principal interlocutor interno con el gobierno cubano. Así, este trabajo demuestra que las tensas relaciones de los 60 fueron sustituidos por el establecimiento de relaciones estables, una normalidad accidentada, lo que llevó a la emergencia de la Iglesia católica como un actor clave en el contexto político cubano actual.

PALABRAS CLAVE: Cuba, Iglesia católica, revolución, mediación.

\footnotetext{
ABSTRACT

This paper discusses the relationship between the Catholic Church and the State in Cuba since the beginning of the revolutionary process (1959) to the present day. In this regard, it examines three key moments: the tension and distance caused by the transition to socialism developed in the country; the rapprochement that culminated with the visit of Pope John Paul II in the 90s, still under the impact of the fall of the Soviet bloc and the international isolation faced by the country, and finally, the latest relations, marked by the visit of the Pope, now emeritus, Benedict XVI and the affirmation of the Catholic Church as the main internal interlocutor with the Cuban government. Thus, this work demonstrates that the strained relations in the 60 s were replaced by the establishment of stable relationship, a bumpy normality,
} 
Dossier América Latina: política y religión which enabled the emergence of the Catholic Church as a key actor in the current Cuban political context.

KEYWORDS: Cuba, Catholic Church, revolution, mediation.

\section{Introducción}

La sociedad cubana, a pesar de sus fuertes vínculos (históricos, culturales, políticos, etc.) con América Latina, tiene una singularidad que hace que sea más compleja la comprensión de su realidad contemporánea, debido al proceso de construcción socialista, desde finales de los años 50, y sus desafíos recientes. Este proceso, además de la profunda transformación política, económica y social, afectó también las relaciones entre la Iglesia y el Estado, determinando la redefinición de una historia secular de profunda influencia de la Iglesia católica, aunque los servicios protestantes y de matriz africana también tenían una presencia importante en el país.

Estas relaciones han ido variando de acuerdo con la dinámica de implementación del socialismo, que ha pasado por varias fases desde la victoria revolucionaria. De este modo, en los años 60, ha predominado una actitud de incomprensión y conflicto en ambos lados. Poco a poco, esta actitud varía para un reacomodo tenso de las relaciones. Por último, asociado con los cambios e impactos resultantes de la caída del bloque soviético, hay un acercamiento entre la dirección revolucionaria y la jerarquía católica, que muestra cierta convergencia de intereses, lo que hace de la Iglesia católica el principal interlocutor interno del régimen cubano (Contreras Garcia: 2013).

Así como en toda América Latina, la Iglesia católica en Cuba tuvo una fuerte presencia. Como ha señalado Bethell (2001), desde la colonización de la América hispánica, la Iglesia tuvo un papel clave en el arreglo colonial. Además de contribuir a la justificación de la colonización, las relaciones entre la Iglesia y el Estado han sido moldeadas por una cercanía profunda que, a diferencia de la iglesia colonial en Brasil, contribuyó a que la Iglesia tuviera una relevancia económica. De esta manera, ella se ha convertido en un importante actor político que debe ser tomado en consideración, ya que cualquier transformación o cambio político podría atañer, en mayor o menor medida, a sus intereses.

La comprensión de la dinámica de la relación entre la Iglesia y el Estado en Cuba, desde los años 60 hasta la actualidad, es el objetivo de este trabajo. Para ello, se estructura de la siguiente forma. En la primera parte, se analizan las primeras etapas de esta relación, tratando de entender la naturaleza del conflicto y distanciamiento. A continuación, se analizan los impactos y transformaciones recientes, en los que hay un acercamiento entre ellos, que culminó con la visita del Papa Juan Pablo II en los años 90, y la promoción de la Iglesia católica como un actor político pertinente y principal interlocutor interno del gobierno cubano. 


\section{Revolución y Religión, Iglesia y Estado: la incomprensión y alejamiento}

La Revolución Cubana fue, sobre todo, una revolución nacionalista que se radicalizó debido a las circunstancias - internas y externas - adquiriendo nuevos contornos que llevaron al proceso de construcción del socialismo. Como señala Sader (2001), parte del programa revolucionario había sido construido y fue revelado en la famosa defensa de Fidel Casto en el juicio del Moncada, conocida como "La historia me absolverá". En esta, además de la denuncia de la realidad dictatorial que tenía el país, se estableció un programa mínimo que se desarrollaría, si hubieran logrado la victoria, siendo retomado después de la Revolución de 1959, y que se puede resumir en los siguientes puntos: la reanudación de la vigencia de la Constitución de 1940, la reforma agraria, el derecho de participación de los trabajadores y empleados en los beneficios de las empresas y de los colonos en los rendimientos de azúcar, la disminución de los precios de alquiler, el juicio de los casos de malversación de fondos públicos y la confiscación de los bienes malversados. Además, señala la necesidad de una reforma integral de la educación, la afirmación de la soberanía del país y la nacionalización de los trusts de electricidad y teléfono (Sader 2001: 31-32).

Ciertamente, la lucha revolucionaria (1956-1959) pudo haber influido en la expansión del programa, sin embargo, al alcanzar el poder, estos cambios, aunque implementados gradualmente, llevaron a la profundización y radicalización de la revolución. Esto porque se refirió a los intereses de los grandes terratenientes y las élites económicas locales, por un lado, pero principalmente de los EE.UU., ya que gran parte de las tierras y las actividades económicas estaba controlada por empresas estadounidenses. Aún así, hay que tener en cuenta que el contexto internacional, marcado por la Guerra Fría, ha indicado que cualquier proyecto de justicia social en la región adquirió el barniz comunista y tenía la oposición de la política exterior de Estados Unidos (Ayerbe 2004). Por lo tanto, mismo siendo una fuente de controversia y polémica no agotada, la Revolución Cubana se hará más radical y, en 1961, es proclamado el carácter socialista de esta preparando el camino para el apoyo soviético.

A lo largo de la primera parte de los 60 , se va conformando una mentalidad basada en la difusión e incorporación del marxismo como guía de los principios revolucionarios, y la incorporación de la institucionalidad socialista, con la estructuración y el desarrollo de las organizaciones de masas (partido, fuerzas militares, federaciones sindicales de mujeres y estudiantes, entre otros), con la adopción del modelo económico estatal y centralizado, con la organización de las autoridades e instancias políticas bajo el liderazgo de Fidel Castro, apoyados en el modelo soviético. Es de destacar que todo esto estaba, al menos en sus primeros años, inmerso en grandes debates y con el intento de construir un socialismo fundamentado en la tradición, la historia y la
Conflicto, diálogo y mediación: un balance de las relaciones la Iglesia y el Estado en la Revolución Cubana

Marcos Antonio da Silva Lucimara Inácio do Prado da Silva 
Dossier América Latina: política y religión perspectiva nacional y no constituyen, por tanto, una mera reproducción del modelo soviético.

Desde entonces, la afirmación de la ideología y el modelo socialista se convierte en el elemento clave, por lo tanto, para entender la relación entre el Estado y la Iglesia en el país, o más específicamente, de la dirección revolucionaria y la jerarquía católica y la tensión y el conflicto que siguió. Las fuentes de tensión provienen de las metas y acciones llevadas a cabo por ambos lados.

La Iglesia católica, fuertemente influenciada por el clero conservador español, poseía razones generales y locales para hacer frente a los cambios desarrollados y que, en algunos casos, llevaron a la oposición. En términos generales, el anticomunismo, afectado por la visión marxista de la religión como opio del pueblo y el ateísmo como elemento presente en el cuerpo clásico de la doctrina, ha generado inevitablemente la desconfianza (y desacuerdos) en relación a los ideales revolucionarios. Por lo tanto, como ha señalado Mayedo (2006), ya en mayo de 1960 el arzobispo de Santiago de Cuba afirmó en su carta pastoral:

Los campos están ya deslindados entre la Iglesia e sus enemigos (...) No puede ya decirse que el enemigo está a las puertas, porque en realidad está dentro, hablando fuerte, como quien está situado en propio predio. No en vano algunos avisados, de percepción más fina, andaban hace ya algún tiempo, alarmados y cautelosos, disponiéndose a luchar con los que tratan de imponer, sin más ni más, el pesado yugo de la nueva esclavitud. (Mayedo 2006: 46)

En el mismo año, el 7 de agosto, los obispos del país produjeron una Circular Colectiva de los Obispos cubanos, para ser leída en todas las iglesias, donde, a pesar del apoyo de ciertos cambios revolucionarios, declararon que:

No se le ocurra, pues, a nadie venir a pedirles a los católicos en nombre de una mal entendida unidad ciudadana, que nos callemos nuestra oposición a estas doctrinas, porque no podríamos acceder a ello sin traicionar nuestros más profundos principios. Contra el comunismo materialista y ateo está la mayoría absoluta del pueblo cubano, que es católico y que solo por el engaño y la coacción podrían ser conducidos a un régimen comunista. (Mayedo 2006: 148)

Por lo tanto, el anticomunismo hizo difícil, si no imposible, algún tipo de entendimiento con el nuevo régimen, sin embargo, otros factores más determinaron el desprendimiento y ruptura. Entre las medidas adoptadas por la dirección revolucionaria dos alcanzaron directamente los intereses de la Iglesia y sus fuentes de ingresos. La universalización de la educación, la promoción de una educación laica y los elementos marxistas, provocó la disminución de los ingresos derivados de las escuelas católicas y la capacidad 
de influencia de la jerarquía. Además, aunque en menor medida, la Ley de Reforma Urbana de 1960, que reduce el costo del alquiler y facilita la adquisición de los mismos por los inquilinos también afectó parte de la renta de la Iglesia en el país. De esta manera, la profundización de los cambios y la adopción de los ideales socialistas establecieron, inevitablemente, una dinámica de conflicto en estas relaciones.

Por el lado de la dirección cubana, los principales factores estaban en el cuerpo teórico del marxismo y en el principal desafío que la revolución enfrentaba. ${ }^{1}$ En gran medida, el marxismo fue construido en el diálogo crítico con el enfoque feuerbachiano que identificó a la religión a una proyección de los deseos humanos, y reafirmando el enfoque materialista del joven Marx que hizo la famosa identificación de la religión como opio del pueblo. Por lo tanto, el marxismo clásico argumentó que la religión era un producto ideológico de los grupos dominantes, que asociado a los dilemas enfrentados por los soviéticos, determinó una postura crítica de la religión en general, y de la Iglesia en particular. Así, como señaló Alonso (2011):

Para la mayoría de la población cubana creyente, el dilema de la década de 1960 se presentó como una contradicción: "El catolicismo o la revolución". Este dilema fue más agudo por el hecho de que la asimilación estatal del marxismo al canon ortodoxo soviético, doctrinalmente ateo, lejos de contribuir a atenuar la incompatibilidad, la generalizaba incluso en términos de "la religión o la revolución". (Alonso 2011: 107)

En el caso cubano, debemos tener en cuenta, además de ese, otros elementos. Para la dirección revolucionaria tenía importancia la constatación de que la Iglesia católica en el país no había denunciado y no se opuso enérgicamente a la dictadura de Batista $(1952-1958)^{2}$, pues como señala Mayedo:

Además, la abstención de la oficialidad eclesiástica había fortalecido los rumores sobre una supuesta simpatía de los obispos y el Cardenal con el batistato. Incluso, algunos condenaban tal silencio al compararlo con las valientes posturas asumidas por las jerarquías católicas de Argentina, Colombia y Venezuela contra las dictaduras militares que habian sometido a esos países latino-americanos en épocas similares. (Mayedo 2006: 138)

1 Una compreensión de las posiciones clássicas del marxismo y de los desafios apuntados por la Teologia de Liberación en América Latina se presenta en el libro de Michael Lowy (1991) Marxismo e teologia da libertação, ed. Cortez.

2 Además, como afirma el embajador Lojendio: "El cubano se fija mucho en las fotografías de los diarios y juzga mucho por lo que en ellas ve. El recuerdo de la figura del Cardenal junto al Presidente de la República General Batista o de la primera dama en actos oficiales, su asistencia a recepciones en el Palacio Presidencial, se les antojan hoy a muchos cubanos, incluso a muchos católicos, manifestaciones de colaboración con el régimen que detestaban..." (Mayedo 2006: 138).
Conflicto, diálogo y mediación: un balance de las relaciones la Iglesia y el Estado en la Revolución Cubana

Marcos Antonio da Silva Lucimara Inácio do Prado da Silva 
Dossier América Latina: política y religión
Por otra parte, como se dijo anteriormente, el proceso de nacionalización (y radicalización), encarnada en las diversas leyes de la época, pero principalmente en aquellas relacionadas con la educación y alquiler, distanció aún más a los interlocutores.

Por último, debido al clima reinante, hubo la sospecha y temor por parte de la dirección revolucionaria de que la Iglesia católica podría ser influenciada por las posiciones políticas de Estados Unidos y contribuir al intento de desestabilizar al gobierno, apoyando la acción de los movimientos de oposición. Según Alonso, el ambiente de tensión entre la Iglesia y el Estado alcanzó su apogeo entre 1960 y 1962 cuando "El gobierno revolucionario marcó su presencia en a la procesión de la Virgen de la Caridad del Cobre (patrona del país), de 1961 en La Habana, convertida en una manifestación política contra él, respondiendo con la deportación a España de un obispo de la arquidiócesis y 131 sacerdotes y religiosos, la mayoría españoles "(Alonso 2011: 108).

En este escenario, la famosa declaración de Fidel Castro "Por la Revolución todo, contra la Revolución nadie" selló el padrón de la relación con la Iglesia y determinó la dinámica del conflicto y la equidistancia, hasta los años 80. Además, la resolución del primer congreso oficial del PCC, en 1975, y la Constitución de Cuba, del año siguiente, reafirmó el carácter ateo del Estado y la crítica de la religión como falsa conciencia de la realidad, contribuyeron a mantener la distancia entre Iglesia y Estado en el país. ${ }^{3}$

Sin embargo, según ha apuntado Alonso (2011), dos cartas pastorales de la Iglesia católica en los finales de los 60, han contribuido a reducir las tensiones, pero no significan un acercamiento eficaz entre ella y el gobierno. La primera mostró las críticas de la Iglesia al bloqueo de Estados Unidos y la segunda afirmaba la posibilidad de interacción y la colaboración entre ellos, especialmente entre cristianos y ateos. ${ }^{4}$ Sin embargo, a pesar de la iniciativa de la Iglesia, sólo en los años 80, habrá el comienzo del clima de normalidad que se consolidará en las décadas siguientes.

Con este fin, dos acontecimientos parecen haber sido fundamentales. El primero asociado a la presencia e intermediación desarrollada por el dominico brasileño Frei Betto, que publicó un libro de entrevistas con Fidel Castro sobre la religión (Fidel y la Religión) que, sin perder la visión tradicional del marxismo, señaló una mayor apertura al fenómeno religioso, en general, y destacó el papel de la Teología de la Liberación en América Latina. El libro y la intermediación de Frei Betto entre las dos cúpulas, la católica y el gobierno, fueron fundamentales para la restauración de esta normalidad, pues como ha mencionado:

3 Aunque, como apunta Contreras Garcia (2013), el Partido Comunista Cubano reconocía la importancia y la convergencia de los adeptos de la Teologia de la Liberación en el contexto latinoamericano de los años 70, la mayoría del clero cubano no tenía este perfil y la actuacción de capa superior de la jerararquía católica, conectada a la Congregación para la Doctrina de la Fé del Vaticano, dirigida por el entonces cardinal J. Ratzinger, contribuyó para mantener la desconfianza interna.

4 Para un análisis de estos y otros documentos fundamentales véase La voz de la Iglesia en Cuba - 100 documentos episcopales, Obra Nacional de la Buena Prensa, México 1995. 
Fidel admitió que la politica revolucionaria, aunque jamás había perseguido las confesiones religiosas, se equivocó en cuanto a la Iglesia Católica. Había 16 años que no concedía audiencia a los obispos. Me preguntó si yo estaría dispuesto a contribuir a la reanudación del diálogo. Estuve de acuerdo, pero eso dependería del episcopado cubano de interés. En 1981, invitado por Casa de las Américas, he pisado por primera vez en La Habana. Sin embargo, el contacto con los obispos sólo se llevaría a cabo en febrero de 1983 cuando la Conferencia Episcopal me invitó a reunirse en el Santuario Nacional de Nuestra Señora del Cobre, cerca de Santiago de Cuba. Estaban presentes el Nuncio Apostólico y los ocho obispos del país. Según Fidel - "Desde el inicio de la Revolución había muchos pecados en ambos lados. Más de nuestro lado que en el lado de la iglesia", admitió. "Yo tenía mis prejuicios contra los obispos y estaba mal informado. Jugaba que el Monseñor Adolfo (Rodríguez) un conservador y reaccionario. En cambio, es un hombre serio con quien se puede hablar". (Betto 2011: 218-219)

Además, la reunión del Encuentro Nacional Eclesial Cubano (ENEC), en 1986, marcó un punto de inflexión en el conflicto, poniendo en juego la capacidad de acercarse y la reconciliación entre la Iglesia y el Estado (Contreras Garcia 2013). El documento final del evento, aunque crítico de las limitaciones al ejercicio de la libertad religiosa, reconoció los esfuerzos del gobierno para proporcionar a los ciudadanos los derechos fundamentales (salud, educación, etc.), generando un clima propicio para el diálogo y el acercamiento entre el gobierno y la Iglesia que, sin embargo, sólo será efectiva en la década siguiente, en el contexto de la crisis interna y el relativo aislamiento a que fue sometida la Revolución Cubana.

\section{Iglesia y Estado en la realidad contemporánea: de la convivencia a la cooperación}

El final del bloque soviético, y en particular de la Unión Soviética, golpeó profundamente a Cuba, debido a los intensos lazos que se gestaron entre el país y la comunidad socialista desde la Revolución Cubana en 1959. Tales lazos profundos habían determinado gran parte de la organización económica, política, militar y social del país (Ayerbe 2004, Sader 2001, Bandeira 1998, Riverend 1990, Coggiola 1998).

La interrupción, involuntaria e inesperada, trajo un doble impacto de gran magnitud. En el ámbito interno, llevó al país a la más grave crisis económica y social desde el advenimiento de la Revolución, y quizás de toda su historia. Esta crisis, sin embargo, sólo reveló otro desafío. En el ámbito internacional, la interrupción de las relaciones comerciales y diplomáticas con los antiguos aliados llevó al país a un relativo aislamiento económico y político en la escena internacional; lo que ha forzado su liderazgo a repensar todo el sistema de las
Conflicto, diálogo y mediación: un balance de las relaciones la Iglesia y el Estado en la Revolución Cubana

Marcos Antonio da Silva Lucimara Inácio do Prado da Silva 
Dossier América Latina: política y religión relaciones internacionales para hacer frente a los efectos de la crisis interna y la reinserción en un nuevo orden que, en gran parte, se mostró adverso a los ideales revolucionarios que la isla caribeña buscaba representar y estimular.

Entre 1990 y 1993, Cuba perdió abruptamente e intensamente el 85\% del mercado que había acompañado al país durante las tres últimas décadas, así como sus principales fuentes de crédito, de asistencia técnica e intercambio de tecnología, lo que provocó fuertes desequilibrios en la balanza de pagos, el retraso económico y el aumento del desempleo y el subempleo, entre otras consecuencias. Además, el país perdió el refugio que significaba, desde el punto de vista político y militar, el orden bipolar y yacía más expuesto a la situación de unipolaridad creada por la caída del socialismo (Sader 2001, Almendra 1998, Mesa-Lago 1998).

Para superar este doble desafío, el liderazgo cubano tuvo que promover acciones que estaban destinadas para la supervivencia económica y la reconstrucción de los vínculos internacionales. En el primer caso, se trataba de reconstruir las bases económicas del país, con la adopción de medidas que garanticen el desarrollo de las actividades económicas y la reanudación de estándares anteriores, que fueron impulsados artificialmente por la ayuda soviética. En cuanto al segundo punto, buscaba reconstruir los lazos políticos y económicos internacionales y desarrollar una política exterior que pudiera responder a los intereses (y necesidades) nacionales.

La reacción del gobierno se puede entender mejor con la evaluación de los cambios políticos desarrollados a lo largo de la década, derivados de los cambios constitucionales implementados por el liderazgo cubano, con la nueva Constitución de 1992. En este sentido, fueron fundamentales los congresos desarrollados por el Partido Comunista de Cuba (PCC) que apuntan las razones y los principios que han guiado la transformación del régimen y sus límites. ${ }^{5}$

Como apuntan Domínguez (2004) y Bandeira (1998), el IV Congreso, que debía realizarse en el año 1990, sólo se produce en el año 1991 a raíz de la crisis provocada por el fin del socialismo y de las dificultades económicas. El principal objetivo fue promover el ajuste del país ante la nueva realidad internacional, generando el desarrollo de una "estrategia de sobrevivencia". El Congreso trató de lograr una evaluación de la caída del socialismo real, afirmando que eso fue el resultado de "errores evitables", subrayando que significó un desastre para el país, acentuado por la aparición de un "mundo unipolar", bajo la hegemonía estadounidense. Finalmente, señalaba que "el objetivo supremo es salvar la Patria, la Revolución y el Socialismo".

Por tanto, el país debía promover un acercamiento a los gobiernos comunistas restantes, llevar a cabo la repatriación de las tropas cubanas en África y América Latina, ampliar el trabajo en el sistema de la ONU, promover la lu-

5 Para el acompañamiento de los discursos y resoluciones de estos congresos del PCC véase V Congreso del Partido Comunista de Cuba, Editora Política, La Habana 1992 y V Congresso del Partido Comunista de Cuba-Resoluciones, Editora Política, La Habana 1998. 
cha contra el dogmatismo y una liberalización religiosa interna y, sobre todo, desarrollar una nueva política económica que, reafirmando los cambios ya en marcha, garantizaba la superación de la crisis por el aumento de las fuentes de capital - en definitiva, fomentar el turismo, la promoción de la liberalización del empleo y la reafirmación y profundización de la nueva política de atracción de inversión extranjera. Tales directrices fueron fundamentadas por los nuevos cambios legales, dentro de los cuales son emblemáticos la Constitución de 1992, la nueva Ley Electoral y la nueva Ley de Inversión Extranjera. En síntesis, se trataba de sobrevivir sin grandes cambios en el sistema o - cuando estos se convirtiesen en inevitables - que fueron controlados por la dirección (PCC 1992, Domínguez 2004, Alonso 1998).

En 1997, se celebró el V Congreso del PCC en que prevalece una sensación de alivio, debido a la sobrevivencia, que se debe al desarrollo de las primeras señales de recuperación económica, lo que reafirmó el hecho de que lo peor había pasado - el clímax de la crisis se produjo entre 93-94, y señaló el comienzo del proceso de recuperación económica, aún errático. Además, el gran debate se centró en los efectos de los cambios y la profundización (o no) de las reformas económicas.

Sin embargo, se trató de demostrar los efectos negativos de ciertas estrategias económicas, tales como el desarrollo de las Unidades Básicas de Producción Cooperativa (UBPC) y se discutió si disminuir o revisar algunas de las reformas adoptadas. Además, el Congreso rechazó una propuesta para abrir más actividades a las pequeñas y medianas empresas. El retroceso no fue mayor sólo debido a la intervención de Carlos Lage, entonces principal líder económico y promotor de las reformas en este ámbito, el cual apuntaba la dificultad de que una nueva retomada del estatismo significaría, entre otros, la caída de las inversiones y el estancamiento del crecimiento, buscando destacar que la eficiencia debería promoverse, desde que preservara la esencia de los valores socialistas (PCC 1992, Domínguez 2004, Alonso 1998).

Fundamental, en el ámbito legal, fue el advenimiento y la profundización de los cambios constitucionales con la aprobación de la nueva Carta, en 1992, que sustituyó la de 1976, que había sido claramente inspirada en la URSS y en el marco del socialismo real. ${ }^{6}$ Esta Constitución estableció un nuevo marco jurídico e institucional y, sobre todo, allanó el camino de las reformas en diversos sectores. La nueva carta se mostró más abierta e inclusiva al buscar legitimar, con carácter retroactivo, los cambios en la forma de propiedad y producción para atraer la inversión extranjera, como apuntado por Domínguez (2004).

El análisis general de esta carta apunta numerosas innovaciones ${ }^{7}$, que marcan un proceso de desideologización que alcanza a las esferas económicas, sociales y políticas.

${ }^{6}$ Cabe señalar que la Constitución de 1992 fue aprobada por el IV Congreso del PCC pero, a diferencia de la de 1976 que fue a referéndum, ésta sólo ha sido ratificada por el pueblo en 2002.

7 Hay que destacar que existen diferentes interpretaciones de estos cambios y que tal debate sigue aún hoy. Para Ayerbe (2004) y Sader (2001) éstos estaban destinados sólo para
Conflicto, diálogo y mediación: un balance de las relaciones la Iglesia y el Estado en la Revolución Cubana

Marcos Antonio da Silva Lucimara Inácio do Prado da Silva 
Dossier América Latina: política y religión
Un primer elemento se refiere al énfasis en el nacionalismo, a expensas de la retórica socialista y, especialmente, del marxismo-leninismo, como guía fundamental de la organización del país. Así, ya en el preámbulo se retira las referencias a los países socialistas, que señalaba: "Guiados y apoyados por el internacionalismo proletario, en la amistad fraternal y la cooperación de la Unión Soviética y otros países socialistas y en la solidaridad de los trabajadores y pueblos de América Latina y el mundo...", siendo substituida por "Guiados por el ideario de José Martí y Lenin y las ideas político-sociales de MarxEngels, apoyados en el internacionalismo proletario, en la amistad fraternal de los pueblos del mundo específicamente de América Latina y el Caribe..." (Constitución de la República de Cuba 1992).

Es decir, se quita la referencia a la doctrina victoriosa del marxismo-leninismo y la Unión Soviética para resaltar José Martí, con énfasis en el nacionalismo como un elemento clave de la política (interna y externa) cubana y enfatizar la unión con los países de América Latina, destacando que el Estado debe servir a todos y para el bien de todos. Además, si el artículo 54 de la Constitución anterior proclamaba que el Estado promovía una "visión científica materialista del universo" en la cual se basaba en sus acciones, el nuevo artículo procura abolir esta referencia.

En segundo lugar, y fundamental, la nueva Constitución trató de atender a todos los cubanos, reduciendo los elementos de marginalización, siendo más abierta e inclusiva, tratando de representar a toda la sociedad y la diversidad de grupos emergentes. En este sentido, merece destacar la nueva mentalidad de la propiedad y producción, así como la libertad religiosa y la estructura del partido, presentando una apreciación más tolerante para las diferentes visiones en la sociedad cubana. Como demuestra Ayerbe (2004), una clara señal de este cambio se refiere al reconocimiento formal, por parte del Estado, del respeto y de la garantía de libertad religiosa según lo indicado en el artículo 8:

El Estado reconoce, respeta y garantiza la libertad religiosa. En la República de Cuba, las instituciones religiosas están separadas del Estado. Las distintas creencias y religiones gozan de igual consideración. (Constitución de la República de Cuba 1992)

Esto significa que el materialismo histórico que había dirigido la acción del régimen a las diferentes creencias y que condujo, durante el periodo anterior, al conflicto con los cultos afro-cubanos y la Iglesia católica, por diferentes

la sobrevivencia, siendo adoptados a regañadientes, y mantuvieron lo esencial y significaron la democratización del régimen. Para Domínguez (2004) y otros representan el mantenimiento del carácter autoritario, debido principalmente a las formulaciones en los artículos 53, 62 y 67 sobre la libertad de expresión y de organización y la capacidad del presidente para legislar y suprimir los derechos, es decir, acondicionando los avances a los fines socialistas. 
razones, se encontraba ahora libre de persecución estatal e incluso podría ser adoptado por los propios miembros del partido. ${ }^{8}$

Así, se muestra más comprensiva y tolerante con las creencias religiosas ${ }^{9}$, lo que contribuye a uno de los grandes momentos de la política exterior del país, el acercamiento con el Vaticano y la realización de la visita papal de 1998, percibida como uno de los eventos que contribuyeron a romper el aislamiento, aún relativo, de Cuba en los años 90. Este evento marca, definitivamente, el proceso de acercamiento entre la Iglesia católica y el Estado cubano, iniciado en la década anterior.

En resumen, la nueva Constitución busca satisfacer las necesidades del nuevo contexto internacional y combinarlos, en lo posible, con los principios socialistas; al buscar eso, trata de ser más incluyente, más tolerante y abierta a las creencias y organizaciones religiosas, basada en el nacionalismo y la reducción del peso del marxismo-leninismo, proporcionando nuevas formas de propiedad y ofreciendo una mayor apertura al capital. Pero no pudo arreglar adecuadamente la relación y la convivencia entre los principios socialistas y la apertura al capital extranjero, además de mantener rasgos autoritarios en ciertos aspectos. Aún, adopta medidas de autonomía local, como una herramienta para salir de la crisis, promoviendo la descentralización de las decisiones administrativas que estaban en contra de la tendencia histórica de la centralización del poder durante la revolución.

De todos modos, es la combinación de avance y retroceso, cambio y continuidad, transparencia y un control eficaz, garantizando la sobrevivencia del régimen en el ámbito político y proporcionando los medios económicos para su reproducción (Sznadjer y Roniger 2001, Domínguez 2004).

Estos cambios contribuyeron a una vuelta a la normalidad, aunque accidentada, superando el conflicto y la desconfianza que habían marcado, hasta entonces, las relaciones entre la Iglesia y el Estado, como señala Alonzo (2011).

Tal normalidad se refleja en la expansión de la estructura y la acción católica. Por lo tanto, en la actualidad, hay 11 diócesis y 3 arquidiócesis, en 1989 eran cinco diócesis y arquidiócesis; aumentó el número de sacerdotes (unos 400) que había permanecido estancado durante años y, en 2010, se abrió un nuevo seminario diocesano, después de décadas; por último, ha ampliado considerablemente el número y la importancia de publicaciones católicas (Alonso 2011). En 2010, según el Instituto de Estudios Socio-Religioso de La Habana, había 600 iglesias católicas contra 900 de otras denominaciones protestantes como metodistas, adventistas, presbiterianos, luteranos, bautistas y otros; pero, hay que destacar que estos templos se distribuyen entre varias

8 En 1997, el gobierno llevó a cabo una encuesta que mostró que el 80\% de la población cree en "algo trascendental", pero sólo el 15\% declaró pertenecer a una denominación religiosa.

9 Para una discusión de la cuestión religiosa en Cuba consulte el artículo Religión, hegemonía y cambios sociales en Cuba, del Centro de Investigaciones Psicológicas y Sociológicas (CPIS), Cuba, 2000.
Conflicto, diálogo y mediación: un balance de las relaciones la Iglesia y el Estado en la Revolución Cubana

Marcos Antonio da Silva Lucimara Inácio do Prado da Silva 
Dossier América Latina: política y religión denominaciones religiosas y, fundamental, la Iglesia católica desempeña el papel de interlocutor interno del régimen (Contreras Garcia 2013).

A pesar de la base social reducida, la Iglesia parece estar contribuyendo al renacimiento de la sociedad civil y, a diferencia de los años anteriores, cuando había conflictos con el régimen, puede ahora realizar sus actividades, incluso criticar ciertos aspectos del régimen, como se desprende de la declaración de los obispos en 1993: "Nosotros, los obispos de Cuba rechazamos cualquier tipo de medida que, con el fin de castigar al gobierno cubano, sirva para agravar los problemas de nuestro pueblo", Además, criticaron la práctica oficial que "lleva a términos de identidad que no pueden hacerse sinónimo, tales como patria y socialismo, cubano e revolucionario" y la limitación de libertades por la "excesiva vigilancia de parte de las agencias de seguridad del Estado que incluso se extienden a la vida estrictamente privada de las personas"; lamentando, inclusive, "el alto número de prisioneros retenidos" ( $\mathrm{La}$ voz de la Iglesia 1995: 274).

Sin lugar a dudas, la piedra angular de esta nueva dinámica por su importancia fue la visita del Papa Juan Pablo II a la isla en 1996. A pesar de las relaciones tensas y conflictivas a lo largo del proceso revolucionario cubano entre la jerarquía de la Iglesia católica del país y los líderes revolucionarios y, en segundo lugar, por el reconocido rendimiento de este líder católico que, para muchos, había contribuido significativamente a la caída de los regímenes comunistas en su nativa Polonia y también en toda Europa del Este, su visita fue determinante para el acercamiento y para la sensación de superación de aislamiento internacional de la isla.

Esta visita ha obtenido un amplio impacto, contribuyendo al desarrollo del objetivo fundamental de la política exterior cubana, y puede ser entendida en dos dimensiones. Por un lado, ha contribuido a la normalización de las relaciones entre la Iglesia y el Estado ${ }^{10}$, que según Calzadilla:

La visita de Karol Wojtyła fue indudablemente un acontecimiento de importancia, calificado de histórico por la prensa extranjera. En su instancia en Cuba el Papa incluyó en su discurso algunos elementos de crítica social y política al tiempo que silenció los logros alcanzados en diferentes campos. Sin embargo, no se justifican presagios que se hicieron sobre los cambios radicales en Cuba, incluso en términos calamitosos. La visita deja un saldo favorable balanceado para el proyecto cubano y para la iglesia. Un propósito evidente del Papa fue reforzar la autoridad de la iglesia local y contribuir a ampliar su espacio, respaldando sus demandas. (Calzadilla 1998: 14)

${ }^{10}$ Para una evaluación de las repercusiones internas de la visita son importantes los artículos de Betto (1998) Wojtyla, huracán sobre Cuba y de Girardi (1998) Cristianismo y Cuba, ambos publicados en la revista "América Libre", no 13, Julio de 1998, Buenos Aires. 
Además, hay que destacar que esta visita contribuyó a superar el aislamiento del país, es decir, el resultado más importante para el gobierno cubano, mediante la movilización de un número relativamente grande de los periodistas que siguieron la visita, para demostrar que el régimen llevaba a cabo un proceso de apertura parcial y, sobre todo, las posiciones tomadas por el Papa en sus discursos, condenando el bloqueo de Estados Unidos y el rechazo al neoliberalismo como una alternativa. ${ }^{11}$

Sin duda, tal acción puede ser comprendida desde diferentes perspectivas. Lo que tratamos de destacar es que ella ha contribuido a la percepción, real o simbólica, de la eficacia de la diplomacia del país que, desde 1979, trató de hacer posible la visita del Papa y que logró su propósito en esa década. En este sentido, describiendo el entorno de la visita, apunta Salazar:

Tanto el gobierno cubano como el Vaticano manifestaron sus satisfacciones por las evidentes coincidencias de puntos de vistas sobre la actual situación del mundo que se habían producido entre ambas personalidades. (...) En ese ambiente, tanto la Conferencia Episcopal de la Isla como el Estado Vaticano se sumaron a la condena de la Ley Helms-Burton. (Salazar 1997: 177)

Desde entonces, aunque marcadas por una normalidad accidentada, las relaciones entre la Iglesia y el Estado han mejorado considerablemente, convirtiéndose la primera en una de las instituciones fundamentales de la sociedad civil en Cuba y el principal interlocutor interno del régimen. Esto permitió a la Iglesia adquirir un protagonismo social, incluso como mediadora entre el gobierno y la oposición (Espacio Laical 2010). A pesar del reconocimiento de que no hay coincidencia plena, consideramos que esas relaciones han adquirido un alto grado de madurez, que sigue reafirmado en las visitas papales posteriores (Benedictus XVI y, ahora, Francisco I).

Este proceso parece haberse acentuado con el ascenso de Raúl Castro, confirmado en 2008, y el establecimiento de un conjunto de reformas, conocido internamente como "la actualización del modelo", lo que indica el camino de una mayor liberalización económica y la transición política, en los marcos de la ideología socialista. Inmediatamente, la Conferencia Episcopal de Cuba emitió una declaración publicada en Granma, que afirmaba:

En estos momentos nuestra oración se eleva para que la Asamblea Nacional del Poder Popular renovada, el Consejo de Estado y el nuevo presidente, Raúl Castro, reciban la luz de lo alto para llevar adelante con decisión esas

${ }^{11}$ Un aspecto importante señalado por Alonso es que: "El actual Secretario de Estado Tarcisio Bertone recordó en su reciente libro sobre la vida de Papa Wojtyla: "Fidel Castro mostró afecto por el Papa, que ya estaba enfermo, y Juan Pablo II me confió que posiblemente ningún jefe de Estado había preparado tanto para una visita de un Pontífice". El autor también comenta que Fidel conocía las encíclicas y los principales discursos del Papa e, incluso, algunos de sus poemas" (Alonso 2011: 111).
Conflicto, diálogo y mediación: un balance de las relaciones la Iglesia y el Estado en la Revolución Cubana

Marcos Antonio da Silva Lucimara Inácio do Prado da Silva 
Dossier América Latina: política y religión medidas transcendentales que sabemos deben ser progresivas, pero que pueden comenzar a satisfacer desde ahora las ansias e inquietudes expresadas por los cubanos. (Declaración de los Obispos de Cuba 2008)

Además, el ex Secretario de Estado, el cardenal Tarcisio Bertone, se ha convertido en el primer representante extranjero a reunirse con el nuevo líder cubano, acentuando la proximidad de la alta jerarquía católica y el gobierno cubano.

Por lo tanto, la alusión de Raúl Castro al diálogo con la Iglesia católica en la inauguración del VI Congreso del PCC en 2011, la visita del Papa emérito Benedicto XVI (2012) y del Papa Francisco (en 2015 y 2016) ${ }^{12}$ parecen sellar la consolidación y normalización, aunque accidentada, de las relaciones entre ambos, confirmando lo que señala Contreras García:

Las relaciones entre la Iglesia Católica y el Estado cubano atraviesan actualmente uno de los mejores momentos de su historia, aunque estas dos instituciones mantienen serias discrepancias sobre cuáles han de ser los derechos fundamentales del ser humano y los principios sobre los que debe sustentarse la sociedad civil. En los últimos años, los obispos de Cuba han tratado de acercar posiciones con el gobierno castrista a través del diálogo, con el doble propósito de recuperar los espacios perdidos al triunfo de la revolución y de contribuir a la adopción de medidas reformistas que puedan facilitar, en el futuro, un proceso de transición hacia la democracia. (Contreras Garcia 2013: 193)

Es de destacar que tal acercamiento demuestra una convergencia, sin precedentes en la historia reciente del país, marcada por beneficios y críticas.

En el primer caso, la dirección cubana parece haber encontrado un interlocutor confiable y más amigable que los grupos disidentes y que le ofrece una mayor legitimidad, interna y externa, necesaria en el nuevo contexto internacional; mientras que para la Iglesia católica, el acercamiento consolida su posición como el principal interlocutor y mediador de los conflictos y los cambios internos que promueve el régimen, potenciando su papel en la sociedad cubana contemporánea. Sin embargo, esta relación enfrenta la crítica de los grupos de oposición, cerca o lejos de la Iglesia católica, ya que consideran demasiado moderadas sus acciones; además, en el gobierno hay sectores que todavía tienen dudas acerca de las verdaderas intenciones y el grado de compromiso de la Iglesia con los ideales socialistas.

Ese papel mediadora de, de los conflictos internos e internacionales se ha combinado con el pragmatismo de la era Raúl Castro y se hizo evidente en el trabajo de la Iglesia católica, a través del Vaticano, en las negociaciones para la reanudación de las relaciones diplomáticas entre Cuba y los Estados Unidos, en 2014. En este caso, debido a la importancia de dicha restauración de los lazos,

12 Además, en 2016, Cuba fue el palco del encuentro histórico entre el Papa Francisco y el patriarca Kirill, de la iglesia ortodoxa rusa, que no se dialogaban desde 1054. 
se puede señalar que tal actuación ha contribuido a la consolidación de los movimientos señalados anteriormente y aumentó la importancia y la presencia de la Iglesia en la sociedad cubana. Además, las posiciones adoptadas por el nuevo Papa, Francisco I, pueden contribuir a la profundización de esta acción. En fin, ese proceso demuestra que, como señala Alonso:

Podemos decir, en este punto, que el catolicismo rescató una influencia institucional y, al mismo tiempo, un lugar significativo en la demografía religiosa cubana. Fue creado un espacio para la Iglesia Católica, proporcionalmente más compartido, con el mundo de las denominaciones protestantes y con la presencia de la religión de origen africano, que no se limita a "santeros" y "paleros", en sentido estricto, sino a través de grandes sectores de la clientela católica. (...) En cualquier caso, el espectro religioso cubano de hoy puede ser lo que refleja los mayores logros, en la historia de Cuba, de la superación de la discriminación y en contribuir a fomentar un clima religioso de la libertad sin diferencias de credos. (Alonso 2011: 114)

De ese modo se puede comprender la normalización de las relaciones y la afirmación de la Iglesia como una de las instituciones fundamentales de la sociedad cubana contemporánea y principal interlocutora del gobierno cubano. Ciertamente hay desafíos que deben ser superados de parte a parte y otros grupos religiosos han emergido, pero por su historia, su importancia y el aporte internacional la Iglesia católica cubana se convirtió en un actor clave del futuro del país.

\section{Conclusión}

A lo largo de este trabajo tratamos de analizar las relaciones entre la Iglesia católica y el Estado en Cuba, teniendo en cuenta el papel de la Iglesia católica, desde el comienzo del proceso revolucionario (1959) hasta nuestros días. En este sentido, tratamos de demostrar que si en los años 60 y 70 las relaciones estuvieron marcadas por la tensión y la equidistancia, en la primera década de este siglo han adquirido un grado de madurez, de confianza y cooperación, aunque persisten focos de conflicto.

La tensión y equidistancia de los años 60 , influidos por el contexto de la época, sólo pueden entenderse si se considera el papel de la dirección revolucionaria y la jerarquía católica, la incompatibilidad de metas y fuentes de desacuerdo. En el caso de la Iglesia, dos elementos determinaron el desencuentro: el fuerte discurso anticomunista, intenso en una iglesia conservadora, y los actos revolucionarios del nuevo gobierno consagrado en las leyes de educación y reforma urbana que afectaron directamente a los intereses de la Iglesia. En cuanto a la dirección revolucionaria, fueron determinantes el ateísmo del marxismo clásico, la visión de que la Iglesia no había denunciado y combatido
Conflicto, diálogo y mediación: un balance de las relaciones la Iglesia y el Estado en la Revolución Cubana

Marcos Antonio da Silva Lucimara Inácio do Prado da Silva 
Dossier América Latina: política y religión la dictadura de Batista y, en menor grado, el temor de que la Iglesia ofreciese protección a los grupos oponentes o pudiese estar influenciada por la publicidad de Estados Unidos.

Desde entonces hasta los 80 , aún teniendo señales de apretura y acercamiento de ambas partes, las dificultades de comprensión y los focos de conflicto han predominado.

Esto ha modificado, efectivamente, a partir de los años 90, debido a los cambios profundos en la política nacional e internacional. En este sentido, la fragmentación del bloque soviético llevó a la dirección del país a un doble desafío: la necesidad de enfrentar la profunda crisis económica y reconstruir las relaciones internacionales. Por lo tanto, era necesario un conjunto de reformas, en varios planes, lo que contribuyó al acercamiento.

De esta manera, se produce en Cuba un proceso de revisión y adaptación de las ideas socialistas a la nueva realidad que alimenta el proceso de reforma, lo que permitirá impulsar el entendimiento y la cooperación entre el gobierno y la Iglesia. La culminación de esta relación se produce con la visita del Papa Juan Pablo II a la Isla en 1996. Para el liderazgo cubano, esa visita significó la consolidación de la estrategia de reintegración en el ámbito internacional y la legitimación de la política interna. Para la Iglesia, esta visita ha consolidado su espacio institucional en la nueva realidad, calificándola como un actor clave en el proceso político actual, lo que sigue siendo reforzado por otras visitas papales.

Desde entonces, hay una normalización de las relaciones y la tensión y la equidistancia han sido sustituidas por el diálogo y la mediación, lo que demuestra una madurez de ambos lados, aunque quedan algunos focos de conflicto. Esa relación puede ser fundamental, internamente, para el futuro de las reformas y de la sociedad cubana en este siglo.

\section{Bibliografía}

Almendra C. C. (1998), A situação econômica cubana diante da queda do Leste Europeu, en: Revolução Cubana: história e problemas atuais, Coggiola, O (ed.). Editora Xamã, São Paulo.

Alonso A. (2011), A Igreja católica, a política e a sociedade, "Revista de Estudos Avançados", IEA/USP, vol. 25, no 72, pp. 107-115.

Alonso Felipe Ruiz (1998), El V Congreso del Partido Comunista de Cuba, "América Latina Hoy", no 18, pp. 61-71.

Alzugaray Treto C. (2003), La política exterior de Cuba en la década de 90: intereses, objetivos y resultados, "Política Internacional", vol. I, no 1, pp. 14-32.

Alzugaray Treto C. (2007), Reflexões sobre o presente e o futuro político de Cuba nos albores do século XXI- uma abordagem a partir da ilha, "Relações Internacionais", IPRI, pp. 89-104. Ayerbe L. F. (2004), A Revolução Cubana. Editora UNESP, São Paulo. 
Bandeira L. A. M. (1998), De Martí a Fidel: a revolução cubana e a América Latina, Editora Civilização Brasileira, Rio de Janeiro.

Bethell L. (2001), História da América Latina - da Independência a 1870, vol. III, EDUSP, São Paulo.

Betto F. (2011), Recuerdos de Cuba: à luz dos 52 anos de Revolução, "Revista de Estudos Avançados", IEA/USP, vol. 25, no 72, pp. 217-226.

Betto F. (1998), Wojtyla, huracán sobre Cuba, "Revista América Libre", no 13, Julio de 1998.

Betto F. (1986), Fidel e a religião, Editora Brasiliense, São Paulo.

Calzadilla Jorge R. (1998), Las relaciones Iglesia-Estado y Religión-Sociedad en Cuba. CIPS, Centro de Investigaciones Psicológicas y Sociológicas, Ciudad de La Habana, disponíble en: <www.clacso.org. $>$.

Coggiola O. (1998), Revolução Cubana: história e problemas atuais, Editora Xamã, São Paulo.

Constitución de la República de Cuba (1992), Constitución socialista reformada en el año de 1992, disponible en: http://www.uniondejuristadecuba.cu/constituciones, fecha de consulta: 20 marzo de 2013.

Contreras Garcia D. (2013), Iglesia Católica y Estado en la República de Cuba: pasado y presente de sus relaciones, "América Latina Hoy", no 63, pp. 177-195.

Declaración de los Obispos de Cuba (2008), disponible en: www.iglesiacubana.org, fecha de consulta: 12 de diciembre de 2013.

Domínguez J. (2004), El sistema político cubano en los noventa, en: La Transición invisible, Bobes V., Rojas R. (eds.), Editorial Océano, Ciudad de México.

"Espacio Laical" (2010), Acerca de la mediación de la Iglesia Católica en Cuba, en: "Espacio Laical", vol. 4, pp. 1-33, disponible en: www.espaciolaical.org, fecha de consulta: 12 de diciembre de 2013.

Girardi G. (1998), Cristianismo y Cuba, "Revista América Libre", no 13, Julio de 1998.

La voz de la Iglesia en Cuba (1995), Cien Documentos Episcopales, Obra Nacional de la Buena Prensa, México.

Lowy M. (1991), Marxismo e Teologia da Libertação, Editora Cortez, São Paulo.

Mayedo Isabel S. (2006), La Iglesia católica en el epicentro de las transformaciones, en: Marxismo y Revolución, Plá León, Aróstegui R., Mely G. (eds.), Ed. Ciencias Sociales, La Habana.

Mesa-Lago C. (1998), Hacia una evaluación de la actuación económica y social en la transición cubana de los años noventa, "América Latina Hoy", no 18, pp. 19-39.

PCC (1992), IV Congreso del Partido Comunista de Cuba, Editora Política, La Habana.

Riverend J. L. (1990). Cuba: do semicolonialismo ao socialismo, 1933-1975, en: América Latina: história de meio século, Casanova P. G. (ed.), Editora UNB, pp. 59-115.

Sader E. (2001), Cuba: um socialismo em construção, Editora Vozes, Petrópolis.

Salazar L. S. (1997), ¿Cuba: aislamiento o reinserción en un mundo cambiado?, Editorial de Ciencias Sociales, La Habana.

Sznajder M., Roniger L. (2001), Política, ethos social e identidad en la Cuba contemporánea, "América Latina Hoy", no 29, pp. 155-178.
Conflicto, diálogo y mediación: un balance de las relaciones la Iglesia y el Estado en la Revolución Cubana

Marcos Antonio da Silva Lucimara Inácio do Prado da Silva 